\title{
Critical Success Factors of Construction Research and Development
}

\author{
Abstract
}

Research and development (R\&D) activities are important to the construction industry to successfully address the challenges placed upon it and to be competitive. Identifying the factors that influence the success of construction R\&D activities is important as such identification would help the research team to concentrate on the most significant and influential factors and the proper management of them to enhance the performance of construction R\&D activities. The critical success factors (CSFs) of construction research and development during its different phases namely initiation, conceptualisation, development and launch and on the project management were evaluated. A questionnaire survey and a series of semi-structured interviews were used to collect the data from academic members and industrial partners who have been involved in construction R\&D activities. It revealed that from the initiation to the launch of the R\&D project, emphasis was placed on the stakeholders' satisfaction. As opposed this less attention was given to satisfying the researchers' requirements during the R\&D project. The principal investigator's role in leading the project and providing sufficient commitment; effective monitoring and controlling of activities, having a proper dissemination plan and effective dissemination of work were also elaborated.

Critical success factors, Research and development, Stakeholder satisfaction 


\section{Introduction}

The contribution of R\&D on the development of the construction industry is immense as it helps to enhance the effectiveness of construction organisations and raise their international competitiveness through technological advances and managerial developments (Hampson and Brandon, 2004). In his report Sir John Fairclough asserts that society needs to benefit from a modern, efficient, high quality construction industry and suggests innovation, driven by R\&D, as the best way forward (Fairclough, 2002). Expanding this view Barrett (2007) states that R\&D can contribute to finding solutions to the challenges faced by the construction industry and making it highly valued by its customers. Thus, he recognises research work as a factor that influences better practice within the industry (Barrett, 2007). Not limiting the importance to just within the UK, R\&D is being identified as a key factor that can develop the construction industries worldwide (Fox and Skitmore, 2007).

Though R\&D activities include a risk component (van Rooij, 2008; Mitchell and Hamilton, 2007), its role in fostering the wealth of society and the construction industry is widely recognised. In some instances R\&D may not rapidly deliver tangible outcomes, nor generate massive profits, but construction organisations and their employees could benefit in the long run by developing their businesses and careers through intangible benefits. Thus, it can be argued that what is required is effective monitoring and controlling mechanisms to minimise the risks associated with such activities and to maximise their contribution rather than rejecting R\&D altogether. In this regard, identifying the factors that influence the success of construction R\&D activities is important. Such identification would help to concentrate on the most significant and influential factors and thereby the proper monitoring and control of them to enhance the performance of construction $R \& D$ activities. 
This paper evaluates the Critical Success Factors (CSFs) of collaborative construction R\&D projects as they go through their life cycle from Initiation, Conceptualisation, Development, and Launch phases and at the Project Management.

\section{Background}

To remain competitive in the market, organisations should ensure their customer expectations are properly met and the future demands of their customers are properly addressed. In this respect R\&D acts as a valuable "input" for the development of organisations (Business Link, 2007). Clients and consumers expect the organisations to search for new ideas and thereby to provide better construction outputs (Lim and Ofori, 2007; Seaden et al., 2003; Gann, 2000). Accordingly, R\&D can lead an organisation to successfully compete in the market through developing new and improved construction materials, products with lower costs, and improved quality.

The contribution from R\&D is recognised in addressing the sustainable goals of the construction industry. Development of environmentally friendly products and materials, waste management methods, energy efficient construction processes and building designs etc. are some of the outcomes of R\&D applications in achieving sustainability (European Construction Platform, 2005). Since R\&D has been identified as one of the vital factors behind the progression of innovation (Carr, 2007; DTI, 2005; DTI, 2004; Roberts, 2002; HM Treasury, 2002), the capacity for innovation within the construction industry can be influenced through the engagement of R\&D activities.

$R \& D$ activities not only generate tangible benefits such as new and advanced construction products, material, processes, but also generate intangible benefits such as creating informal contacts, membership of international networks, and facilitating knowledge transfers. Some of the intangible benefits of research activities are implied yet unspoken 
between stakeholders involved in them (Gilkinson and Barrett, 2004). Gilkinson and Barrett (2004) assert that people take on board the knowledge and good practices from research workshops and seminars to further strengthen the processes within their own organisations. This supports the view of Cohen and Levinthal $(1989,1990)$ who state that R\&D activities improve an organisation's absorptive capacity i.e. the ability to identify, absorb and exploit new information from the internal or external environment. This has led them to build up their manpower and improve their organisational capabilities, leading to increased productivity and efficiency and in the end to have a competitive advantage in the market. Lim and Ofori's (2007) study revealed construction organisations that engaged in R\&D activities gained intangible benefits such as the development of good rapport with the clients, recognition and prestigious status. In addition, Gilkinson and Barrett (2004) observed that such knowledge transference has enabled organisations to change their processes, strategies, and reconsider their existing processes to reduce waste, cost and time. These intangible benefits of R\&D work would help the research community in initiating successful partnerships, and thereby initiating and engaging in successful research activities to address the problems of the construction industry as a whole. Moreover, Seaden (2002) asserts that the dissemination of construction research findings would benefit the industry as a whole and its clients.

Fairclough (2002) highlights the need for developing a strategic vision supported by an R\&D framework to improve the performance of the construction industry. Similarly, creating a R\&D culture to maximise the efficiency and effectiveness of construction activities are highlighted by Hampson and Brandon (2004). In their study Hampson and Brandon (2004) identify "leadership in R\&D" as the "overarching vision" which facilitates the achievement of the other visions of the construction industry. This emphasises the significance of R\&D in accomplishing the overall goals and objectives of the construction industry. Furthermore, when considering the role it plays within construction industry, it can be argued that its 
agenda cannot be narrowed down to the processes or initial costs of buildings but needs to address a wider spectrum of areas such as health and safety issues, sustainable development, and economic growth.

Despite the importance of R\&D as discussed above, its value is being questioned. Sometimes the outcomes of R\&D are not accepted universally (Twiss, 1992). Furthermore, in some instances R\&D produces unexpected results that fall outside the business strategy, thus leading the organisation to frustration and incurring financial losses (van Rooij, 2008; Mitchell and Hamilton, 2007). Within construction R\&D Gilkinson and Barrett (2004) revealed that some of the industrial partners involved in their study claimed the research activities they were involved in had no impact on their businesses. Additionally, R\&D activities incur overhead costs in marketing, additional time and resources to search into the commercial opportunities of various research proposals (Seaden, 2002). Courtney (1999) claims that even though the costs of research are certain, rewards of research are uncertain. Seaden (2002) also acknowledges that there is little profit from construction research work. Similarly, a group of contractors who participated in a study carried out by Lim and Ofori (2007) revealed that the financial risk involved in research activities has restrained them from funding construction R\&D activities. Further, Guerrera and Waters (2006) report that money spent on R\&D activities is wasted when no clear link between such investments and financial performance is established. As a result of the risk associated with R\&D and the utilisation of resources, some tend to view it as an alternative rather than a core part of their business (Roberts, 2002).

As discussed above R\&D activities are critical in safeguarding the success of the construction industry within the competitive market. These activities facilitate the construction industry in successfully addressing the challenges placed upon it through new and advanced processes, materials and products; improved services and management 
activities and improved operations of construction organisations so as to successfully compete in the market place and to raise their self-image.

\section{Success factors of research and development in general}

Chan et al (2002) define success as the degree to which project goals, objectives and expectations are met. Success could be viewed from different perspectives depending on the goals related to a variety of elements, including technical, financial, education, social, and professional issues (Lim and Mohamed, 1999). Lim and Mohamed (1999) distinguish success criteria and success factors, where the former refers to a set of standards or principles within which the success can be judged and the latter refers to the set of circumstances and factors, which could influence the attainment of the success criteria. Cooke-Davies (2002) also differentiates success criteria and success factors. According to him, success criteria is the measure that could be used to judge the success or failure of a project/business and success factors are the inputs to the management system that leads directly or indirectly to the success of the project/business. Among these, the most influential factors needed for the attainment of the overall goals can be defined as the critical success factors (CSFs).

For a new venture (product, process, service) to be successful, it needs to be effectively moved forward through its life cycle from initiation to launch. This effective transference depends on a number of success factors. Cooper and Kleinschmidt (2007) assert that a high quality, rigorous new product development (NPD) process which consists of thorough upfront work, tough decision points, sharp early product definition and flexibility as the strongest drivers. The need for human integrity in making discoveries, creating new products, processes and services is widely accepted, highlighting the availability and ability of people as one of the crucial factors for successful R\&D effort (Cooper and Kleinschmidt, 2007; Roberts, 2002). Other than the human resource, Cooper and Kleinschmidt (2007) 
identify the availability of financial resources as another factor, which significantly influences the NPD process. The management of R\&D activities has become complex as it addresses the needs of various stakeholders thus requiring a contribution from multidisciplinary groups. Therefore, successful accomplishment of new ventures requires effective management of constraints of the stakeholders. Accordingly, the proper management of interdisciplinary team work (Sawhney and Prandelli, 2000), leadership styles and work environment (Shim and Lee, 2001) are also revealed as factors behind the success of R\&D efforts.

Investigation carried out by Lester (1998) reveals 16 CSFs, which centre on five main categories: senior management commitment; organisational structure and processes; attractive new product concept; forming the venture teams; and project management. These factors are derived from evaluating an early stage of NPD when there is a greater degree of uncertainty. Work carried out by Cooper (1999) considers the success factors needed at the business unit level. After benchmarking factors that drive and obstruct effective NPD, he disclosed 12 success factors such as build in the voice of the customer; seek differentiated, superior product; sharp, stable, and early product definition; a well planned, adequately researched, and proficiently executed launch etc. (see Cooper, 1999). Sun and Wing (2005) linked the success factors with the life cycle of NPD and ranked them according to their importance.

The above section identified the success factors of R\&D activities in general. Accordingly, the following section discusses the success factors with particular reference to construction R\&D. 


\section{Success factors of construction research and development}

In terms of the construction research base, Fairclough (2002, p: 17) raises the following questions; "is the construction research base in a fit state to tackle the most critical issues of the 21st century? Does it have the right people, the right organisation, or the right vision? Does it have the right skills?" Lack of skilled people in construction R\&D organisations has resulted in inadequate support for ongoing R\&D activities and a reduction in the absorption capacity to implement good practices developed in other organisations/disciplines. Similarly to Fairclough (2002), Conceicao and Heitor (2002) also assert the need for skilled employees to implement the good ideas. Skilled people therefore can be identified as one of the success factors for construction R\&D. Further, supporting the researchers by providing facilities to attend seminars, conferences, and training activities to enhance their skills and knowledge are identified as important factors for effective construction R\&D (Dulaimi et al, 2002).

The need for clear operational objectives, which are shared by the participants of the R\&D work is identified by CRISP (2004) as another factor for construction R\&D to be successful. They argue that clear objectives would not overwhelm the parties involved by giving unachievable expectations or inappropriate targets which cannot be met. Further, having clear timeframes for R\&D work would determine and allocate adequate resources (CRISP, 2004). Innovation by its nature is highly risky. Thus, R\&D, which leads to innovation can often fail or generate unexpected results. Therefore, for research work to be successful, creating a "no blame culture" and sharing the cost of failure of R\&D work is emphasised (CRISP, 2004; Dulaimi et al, 2002). Fairclough (2002) asserts that lack of vision/strategy within construction research base as a factor that negatively affects R\&D performance. A clearly defined and transparent R\&D strategy communicates and guides employees towards achieving the common goals of the organisation. Moreover, creating effective links 
between academia and industrial partners is a key factor, which positively influences construction R\&D activities (Gilkinson and Barrett, 2004). Securing long-term funding has been identified as one of the main factors that can contribute to the success of construction R\&D activities (Hampson and Brandon, 2004). Research carried out by Gray and Davies (2007) revealed that measurement against targets, continuous improvement of innovation, teamwork, selecting and generating new knowledge, innovation performance management, developing the right teams are all important factors which influence the success of project-based innovation in construction.

Studies carried out in other disciplines, such as manufacturing, suggested that there could be a gap between the factors that are important and those that are implemented (Sun and Wing, 2005). Lack of knowledge of the success factors could lead to lack of implementation in practice. The success factors identified from the general literature review share a common view of what is necessary for the successful development of a new venture but they are not exactly the same for construction industry. In reality, it is difficult to generate a common set of success factors as they could vary depending on the industry, the type of new venture and the level of analysis (project level, process level). The unit of analysis of the majority of previous studies undertaken in other disciplines was at the organisational level. However, there can be practical issues in construction R\&D activities when they go though initiation to launch phases and in the project management. Therefore, identifying the CSFs during initiation, conceptualisation, development and launch phases and at the project management stage is important.

\section{Method}

The unit of analysis of the study was based around collaborative construction R\&D projects. Accordingly, the data was gathered from Principal Investigators, Researchers and Industrial Partners who have been involved in collaborative construction R\&D projects. As the first 
step for identifying the CSFs, 13 semi-structured interviews were carried out with Principal Investigators (5 interviews), Researchers (5 interviews) and Industrial Partners (3 interviews). NVivo software was used to derive the success factors from the interview transcripts. By using the NVivo software, the interview transcripts were scrutinised to identify the main concepts regarding the success factors of construction R\&D. The main concepts generated from interview transcripts were assigned with an appropriate code to represent the success factors. In addition to the semi-structured interviews, an extensive literature review was carried out on the CSFs in other disciplines. Thereafter, by combining the success factors gathered from empirical investigation via semi-structured interviews and literature review, a questionnaire was compiled (Refer to Table 1 for the response rate of the questionnaire survey). Within the questionnaire, the success factors were structured according to the phase of the construction R\&D project, namely Initiation, Conceptualisation, Development, Launch and for the Project Management.

Table 1: Response rate for the questionnaire survey

\begin{tabular}{|l|c|c|c|}
\hline \multicolumn{1}{|c|}{ Category } & $\begin{array}{c}\text { Number of } \\
\text { questionnaires sent }\end{array}$ & $\begin{array}{c}\text { Number of } \\
\text { responses received }\end{array}$ & Response rate \\
\hline $\begin{array}{l}\text { Principal } \\
\text { Investigators and } \\
\text { Researchers }\end{array}$ & 55 & 34 & $62 \%$ \\
\hline Industrial Partners & 74 & 26 & $35 \%$ \\
\hline
\end{tabular}

A five-scale Likert scale was used to capture the importance of the success factors (refer to Table 2). For the scales, a "no opinion/not applicable" column was added so that the tendency for giving an inaccurate answer when the respondents lacked knowledge or an opinion for a particular question was minimised (see Krosnick, 2002). Table 2 shows the values assigned for the Likert scale used for this study. 
Table 2: Values assigned for the Likert scale in the questionnaire

\begin{tabular}{|l|c|c|c|c|l|l|}
\hline Scale & Unimportant & $\begin{array}{l}\text { Of the little } \\
\text { important }\end{array}$ & $\begin{array}{l}\text { Moderately } \\
\text { important }\end{array}$ & Important & $\begin{array}{l}\text { Very } \\
\text { important }\end{array}$ & $\begin{array}{l}\text { No } \\
\text { opinion/ } \\
\text { N/A }\end{array}$ \\
\hline Value & 1 & 2 & 3 & 4 & 5 & 99 \\
\hline
\end{tabular}

The responses received from the questionnaire regarding the importance of the success factors were subjected to two filtering stages to derive the CSFs: firstly by considering the overall mean value and secondly based on the Asymptotic significance generated from the Wilcoxon signed rank test results. The Wilcoxon signed rank test is a non-parametric method to test the differences of two related variables when the subject (dependant category) is measured on two occasions or under different conditions (Hill and Lewicki, 2007; Pallant, 2001). During the first filtering stage, the success factors with a mean value of less than 4 were excluded from further analysis as they were considered not to be critical to the success of the construction R\&D project. This elimination was done as the factors with a mean value less than 4 belong to unimportant (value 1), of the little important (value 2) or moderately important (value 3) based on the assigned values of the questionnaire survey analysis (refer to Table 2). Following this, during the second filtering stage Wilcoxon signed rank test was used for the remaining success factors i.e. the factors that have an overall mean value above 4. By taking a consecutive pair of data, the Asymptotic significance was calculated. The Asymptotic significance shows an estimate of the significance of differences within attributes being tested (Pallant, 2001). Generally, Asymptotic significance less than 0.05 is considered as indicating a significant difference between the attributes being tested. Accordingly, the paired data which showed an Asymptotic significance $<0.05$ was considered as responses having a significant difference regarding the importance of the success factors, hence such factors were considered as not critical for the success of construction R\&D projects (Please note that in Table 3, Asymptotic significance was not calculated for the non-critical success factors). 
This section discussed the construction and the analysis techniques used for the semistructured interviews and questionnaire survey. The following section presents the findings of the study.

\section{Findings}

\section{Critical success factors of construction research and development}

Table 3 presents the CSFs identified from the empirical investigation of this study. The success factors identified as non-critical for construction R\&D projects are shown in italics. The study revealed that at the initiation and conceptualising phases, emphasis is placed on laying a proper foundation for the research work through the establishment of a clear research problem which would address a current issues of the construction industry; carrying out feasibility studies about the research project as such studies would help to foresee the success of ideas in the long term; ensuring the clarity and focus of the research work for the smooth flow of the research work and to make valuable contributions for the parties concerned. The above empirical data shows the need for establishing the research problem clearly from a good theoretical background via a thorough and rigorous process of literature review. The study carried out by Cooper and Kleinschmidt (2007) also revealed the importance of undertaking upfront homework in the form of market analysis, business analysis, customer research etc. Further, selecting a competent team to engage in the construction R\&D activities was identified as critical at the initiation phase.

Insert Table 3 here

When the research team joins the R\&D project at the conceptualising phase and when the actual development of the research objectives starts, the characteristics and skills of the team members, their behavioural and motivational issues, contribution and commitment make by the team members towards the project become vital for the success of 
construction R\&D activities. The importance of a skilled team in construction R\&D work is well emphasised by the seminal work of Fairclough (2002). Similarly, the empirical data also established the importance of having adequate resources, especially the human resource at the conceptualising and development phases.

The need for establishing specific mechanisms to check whether the R\&D project is achieving its aim and objectives was emphasised at the conceptualising phase. These opinions match well with Lorch (2000) and Seaden and Manseau (2001) who state that the lack of methods to measure the progress of construction R\&D projects and lack of links between the utilisation of resources and the contribution of team members have negatively affected the success of R\&D work. Having a well established operational procedure was identified as important during the development phase. Such a plan would identify the proper communication channels, monitoring mechanisms, risk management strategies, detailing the activities involved during the each phase of the R\&D project and the decision and milestone points which are crucial for progress of the R\&D work. Similarly, Cooper and Kleinschmidt (2007) also revealed the importance of having a high quality new product development process. However, they claim that the mere existence of a new product process would not develop performance, but that the quality and nature of the process with inbuilt best practices would yield the success. Being flexible and responsive to the changes encountered during the construction R\&D project was also identified as critical during the development phase.

The need for establishing a dissemination plan at the conceptualising phase and the existence of a dissemination plan at the launch phase was identified as critical for the success of construction R\&D activities. Such a plan could identify the targeted audience and beneficiaries of the research activity thus ensuring the results properly reached the expected audience and beneficiaries in order to make a valuable impact. Throughout the 
$R \& D$ project, the importance of project management such as effective communication; collaboration; planning, controlling and organising of activities; carrying out continuous reviews; and resource management were emphasised.

From the initiation to the launch of the R\&D project, emphasis was placed on the stakeholders' (industrial partners and funding bodies) needs through the proper identification of their requirements during the initiation and conceptualisation and satisfaction of their requirements during the development and launch phases. As opposed to the prominence given to the satisfaction of the stakeholders, the empirical investigation revealed that less attention was given to satisfying the researchers' requirements. It can be argued that, as a whole, more emphasis is placed on providing value for the stakeholders as their satisfaction could lead to the creation of long term partnerships, guaranteeing continuous funding, rather than considering the requirements of the researchers. Furthermore, the principal investigator's role in leading the project and providing sufficient commitment in arranging the necessary resources and carrying out required negotiations within the team members was elaborated. Research carried out in other disciplines also witnesses the commitment and leadership of senior managers in organising the resources, thus playing a central role in the decision making and reviewing processes (Cooper and Kleinschmidt, 2007; Lester, 1998). In contrast, Sun and Wing's (2005) work revealed commitment of the senior management was among the least important factors for effective NPD work.

\section{Conclusion}

A number of CSFs were identified for the collaborative construction R\&D projects. At initiation and conceptualising phases, emphasis is placed on laying a proper foundation for the research work through establishment of a clear research problem and ensuring clarity and focus of the research work. During the conceptualising and development phases of the 
collaborative construction R\&D projects, skills, commitment and motivation of the team members become vital for the success of the project. Having adequate resources, especially human resources, was highlighted at the conceptualising and development phases. At the launch, effective dissemination of the work was emphasised so that the beneficiaries could benefit from the research results while making a positive impact towards the community. Throughout the R\&D project, the importance of project coordination and resource management were emphasised.

The CSFs identified from the empirical investigation have both similarities and differences with those identified in studies carried out in other disciplines. Some of the similarities can be listed as commitment of the principal investigator, proper up-front work, committed and skilled research teams, need for mechanisms to monitor and control the R\&D projects etc. However, some of the CSFs of construction R\&D projects disclosed were not highlighted in studies carried out in other disciplines. They include satisfying the requirements of funding bodies and industrial partners, establishment of a dissemination plan and the effective dissemination of work.

Even though there are number of studies carried out in the area of CSFs in other disciplines, not much work has been identified within construction R\&D. This study contributes to the knowledge by revealing CSFs of collaborative construction R\&D projects from initiation to launch phases and at the project management. The identification and analysis of CSFs of this study leads to two main benefits. Firstly, to identify the critical factors which influence success of the construction R\&D activities. This ensures the critical areas that are needed for effective and efficient construction R\&D are adequately looked after. Secondly, the identification of CSFs leads to recognition of the "few factors" which could influence the performance improvement of construction R\&D activities. Hence, identifying CSFs could 
lead the research team to facilitate the effective implementation of CSFs within construction R\&D project by providing supporting facilities for their implementation.

\section{References}

Barrett, P. 2007, Revaluing Construction: a holistic model, Building Research and Information, 35.3, 268-286

Business Link, 2007, Manage your research, design and development, (accessed: $12^{\text {th }}$ January 2007), available from: http://www.businesslink.gov.uk/bdotg/action/detail

Carr, M. 2007, R\&D score board 2007, Department for innovation, universities and skills, (accessed: Feb 2008), available from:

http://www.innovation.gov.uk/rd scoreboard/default.asp?p=2

Chan, A.P.C., Scott, D., and Lam, E.W.M. 2002, Framework of Success Criteria for Design/Build Projects, Journal of Management in Engineering, 18.3, 120-128

Cohen, W.M., and Levinthal, D.A. 1989, Innovation and learning: the two faces of R\&D, The Economic Journal, 99(397), 569-596

Cohen, W.M., and Levinthal, D.A. 1990, Absorptive capacity: a new perspective on learning and innovation, Administrative Science Quarterly, 35(1), 128-52

Cooke-Davies, T.J. 2002, The "real" success factors on projects, International Journal of Project Management, 20.3, 185-190

Cooper, R.G. 1999, From experience: the invisible success factors in product innovation, Journal of Product Innovation and Management, 16.2, 115-133

Cooper, R.G., and Kleinschmidt, E.J. 2007, Winning businesses in product development: the critical success factors, Research Technology Management, 50(3), 52-66 
Courtney, R.G. 1999, Innovative ways of funding construction research: an ideas paper, Construction research and innovation strategy panel, (accessed $21^{\text {st }}$ June 2005), available from: http://ncrisp.steel-sci.org/Publications/9913fpRC.pdf

Conceicao, P., and Heitor, M.V. 2002, Systems of innovations and competence building across diversity, in Shavinina, L. V. (Ed), International Handbook of Innovation, (accessed $20^{\text {th }}$ January 2006), available from: http://in3.dem.ist.utl.pt

CRISP, 2004, What kind of research and innovation strategy does UK construction need? (accessed March 2005), available from: http://ncrisp.steel-sci.org/Publications/resin260404.pdf

Department of Trade and industry (DTI), 2004, Construction Research Programme Annual Report 2003/4, DTI, (accessed $11^{\text {th }}$ June 2005), available from: http://www.dti.gov.uk/construction/research/2004chapterone.htm\#Innovation\%20Revi $\underline{\text { ews }}$

Department of Trade and Industry, 2005, Construction Sector Unit's Industry Innovation Team Summary, (accessed 10 $10^{\text {th }}$ June 2005), DTI, UK, available from: http://www.dti.gov.uk/construction/research/researchteam.htm

Dulaimi, M.F., Ling, F.Y.Y., Ofori, G., and De Silva, N. 2002, Enhancing integration and innovation in construction, Building Research and Information, 30(4), 237-247

European construction platform, 2005, Strategic research agenda for the European construction sector - achieving a sustainable and competitive construction sector 2030, Draft version, (accessed: $10^{\text {th }}$ August 2005), available from: http://www.ectp.org

Fairclough, J., 2002, Rethinking construction innovation and research: A review of government $R$ and $D$ policies and practices, Department of Trade and Industry, London 
Fox, P., and Skitmore, M. 2007, Factors facilitating construction industry development, Building Research and Information, 35(2), 178-188

Gann, D.M. 2000, Building innovation, Thomas Telford, London

Gilkinson, N., and Barrett, P. 2004, The unanticipated impacts of research on practice, $C I B$ world congress, $2^{\text {nd }}-7^{\text {th }}$ May, Canada

Guerrera, F., and Waters, R. 2006, R\&D spending frenzy may be a waste of money, Financial Times, (accessed 10th January 2007), available from: http://www.ft.com

Gray, C., and Davies, R.J. 2007, Perspectives on experiences of innovation: the development of an assessment methodology appropriate to construction project organisations, Construction Management and Economics, 25(12), 1251-1268

Hampson, K., and Brandon, P. 2004, Construction 2020: A vision for Australia's property and construction industry, CRC Construction Innovation, Australia

Hill, T., and Lewicki, P. 2007, STATISTICS Methods and Applications. StatSoft, Tulsa, (accessed: $\quad$ February 2008), available from: http://www.statsoft.com/textbook/stathome.html

HM Treasury, 2002, Investing in Innovation: A strategy for science, engineering and technology, (accessed March $5^{\text {th }}$ 2005), available from: http://www.hm-treasury.gov.uk

Krosnick, J.A. 2002, The causes of no-opinion responses to attitude measures in surveys: They are rarely what they appear to be. In R.M. Groves, D.A. Dillman, J.L. Eltinge, \& R.J. A. Little (Eds), Survey nonresponse, John Wiley \& Sons, New York

Lester, D.H., 1998, Critical success factors for new product development, Research Technology Management, 41.1, 16-21 
Lim, J.N., and Ofori, G. 2007, Classification of innovation for strategic decision making in construction businesses, Construction Management and Economics, 25.9, 963 - 978

Lim, C. ., and Mohamed, M.Z. 1999, Criteria of project success: an exploratory reexamination, International Journal of Project Management, 17.4, 243-248

Lorch, R. 2000, Improving the communication of academic research to the construction industry, Construction research and innovation strategy panel, (accessed $20^{\text {th }}$ February 2006), available online from: http://ncrisp.steel-sci.org/Publications/9916frLo.pdf

Mitchell, G.R., and Hamilton, W.F. 2007, Managing R\&D as a strategic option. Research Technology Management, 50.2, 41-50

Pallant, J. 2001, SPSS survival manual. A step by step guide to data analysis using SPSS for windows (Version 10-11). Open University Press, Buckingham

Seaden, G. 2002, Changing more than R\&D: responding to the Fairclough Review, Building Research and Information, 30.5, 312-315

Roberts, G. 2002, SET for success: The supply of people with science, technology, engineering, and mathematics skills, HM Treasury, UK

Seaden, G., and Manseau, A. 2001, Public policy and construction innovation, Building Research and Information, 29.3, 182-196

Seaden, G., Guolla, M., Doutriaux, J., and Nash, J. 2003, Strategic decisions and innovations in construction firms, Construction Management and Economics, 21.6, 603-12

Sawhney, M., and Prandelli, E. 2000, Communities of creation: managing distributed innovation in turbulent markets, California Management Review, 42.4, 45-69 
Shim, D., and Lee, M. 2001, Upward influence styles of R\&D project leaders, IEEE Transactions of Engineering Management, 48.4, 394-414

Sun, H., and Wing, W. . 2005, Critical success factors for new product development in the Hong Kong toy industry, Technovation, 25.3, 293-303

Twiss, B. 1992, Managing technological innovation, 4th edition, Financial Times Pitman, London

van Rooij, A. 2008, How R\&D helped transform DSM, Research Technology Management, $51.1,43-48$ 